\title{
REVIEW
}

\section{Photodynamic therapy: shedding light on restenosis}

\author{
R Mansfield, S Bown, J McEwan
}

Cardiovascular Repair and Remodelling Group, The Hatter Institute, Royal Free and UCL Medical School, Middlesex Street, London W1N 8AA, UK $\mathrm{R}$ Mansfield J McEwan

National Medical Free and UCL Medical School

$S$ Bown Dr Mansfield

r.mansfield@ucl.ac.uk

Accepted 25 June 2001 Hospital, Mortimer Laser Centre, Royal

Correspondence to:

The major limitation of the long term success of percutaneous coronary interventions is the development of restenosis, which occurs in $30-50 \%$ of patients within six months. ${ }^{12}$ Restenosis is the result of a complex pathophysiological process in the arterial wall in response to balloon dilatation or stent insertion. For many years the hallmark of this response to injury was considered to be the development of intimal hyperplasia resulting from the proliferation and migration of smooth muscle cells from the arterial media. ${ }^{3}$ More recently, it has become clear that this is not the only factor involved. Other key aspects in the development of the restenotic lesion are the extracellular matrix, elastic vessel recoil, and arterial remodelling. ${ }^{4}$ While our understanding of the processes induced by balloon injury has improved, treatment strategies to limit this have been disappointing in clinical practice. ${ }^{5}$ Stenting, which is now used in up to $80 \%$ of all coronary interventional procedures, has almost eliminated problems from elastic recoil and has reduced restenosis rates, but neointimal hyperplasia around stent struts can still lead to in-stent restenosis. ${ }^{6}$

Intracoronary brachytherapy is one technique that has proved promising in the prevention of restenosis using either catheter based systems for radiation delivery or radioactive stents. ${ }^{7}$ Concerns have been expressed about late thrombotic occlusion after brachytherapy. ${ }^{8}$ However, the prolonged use of antiplatelet drugs may control this problem. Brachytherapy is probably the best option for treating restenosis currently available. Nevertheless, it would

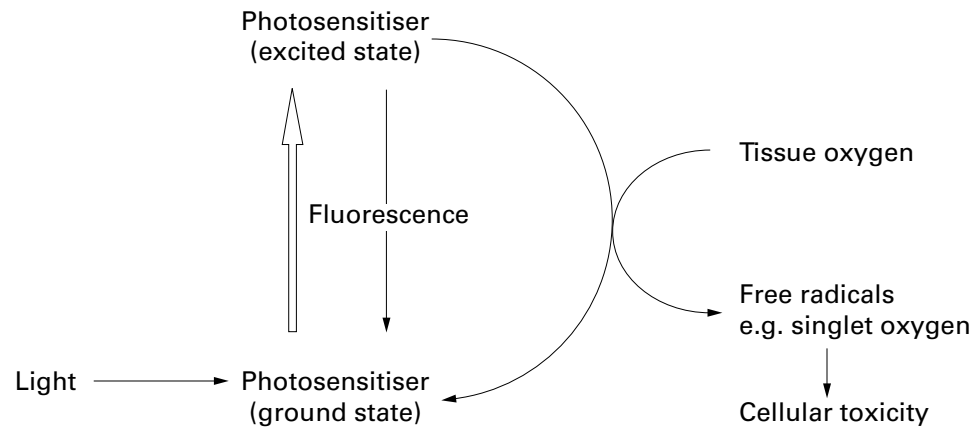

Figure 1 Mechanism of action of photodynamic therapy. Photosensitising agents are activated by light of a specific wavelength. In its excited state the photosensitiser reacts with tissue oxygen to yield various reactive oxidative species, inducing specific cellular and extracellular effects that lead to inhibition of restenosis (see text). The emission of fluorescence as the photosensitiser decays back to its ground state can be used to study the tissue distribution of the sensitiser. be attractive to find a method of preventing restenosis after percutaneous intervention that does not involve ionising radiation or prolonged drug treatment. Photodynamic therapy (PDT), which in contrast to brachytherapy uses non-ionising radiation, is emerging as another possible strategy.

\section{Photodynamic therapy}

PDT involves the interaction of a photosensitising drug, light, and tissue oxygen ${ }^{9}$ (fig 1). Photosensitising agents, many of which are porphyrins or chemicals of similar structure, can be given either topically or systemically. At therapeutic concentrations most photosensitisers have no discernable effects in isolation and require the local application of light at a wavelength that matches the absorption characteristics of the sensitiser. The timing of light delivery following sensitisation is crucial for achieving the desired biological response, and varies with the pharmacokinetics of individual sensitisers. Light - usually in the form of red light from a laser-is delivered at a power that avoids the thermal effects that were a feature of early laser angioplasty. When activated by light, the photosensitiser is transformed into an electronically excited state that can transfer its energy either to tissue oxygen to generate singlet oxygen, or to other biomolecules to yield other free radical intermediates. The short half life $\left(0.6 \times 10^{-6} \mathrm{~s}\right)$ and diffusion distance $(0.1 \mu \mathrm{m})$ of singlet oxygen and other active species means that cellular effects are highly localised to the site where these species are produced. ${ }^{10}$ The activation of photosensitisers incorporated into cell membranes results in swelling, bleb formation, and shedding of vesicles, as well as in the inhibition of membrane transport systems such as $\mathrm{Na}^{+} / \mathrm{K}^{+}$ATPase. Other sites affected include mitochondria, the Golgi apparatus, the rough endoplasmic reticulum, and lysosomes. ${ }^{9}$ Cytotoxicity is mediated at a cellular and subcellular level and may occur by apoptosis or necrosis. In vitro data confirm that PDT induces apoptosis in cultured human vein endothelial cells - an effect mediated by the release of cytochrome $c$ and caspase activation. ${ }^{11}$ Similarly the principal cytotoxic mechanism resulting from PDT of cultured vascular smooth muscle cells was apoptosis. ${ }^{12}$ In vivo evidence of apoptosis is discussed below. 
Most photosensitisers are excluded from the cell nucleus and while small DNA breaks have been reported after PDT, DNA damage does not seem to be a major feature and the risk of mutagenicity is low. ${ }^{9}$ This is one of the major benefits of using red light, where the photon energy is too low to cause DNA damage, in contrast to light in the ultraviolet, $x$ ray, or $\gamma$ ray part of the electromagnetic spectrum.

Most work on PDT to date has been in oncology. With the photosensitiser porfimer sodium (Photofrin), PDT is approved in the USA for the palliation of obstructive oesophageal tumours (when all other treatments have failed) and for early stage, inoperable lung cancer. Several other photosensitisers are at an advanced stage of clinical trials for a range of malignant and premalignant conditions of the skin and internal organs, as well as for some non-malignant conditions such as age related macular degeneration. ${ }^{13}$

There has been interest in PDT and arterial disease since the $1980 \mathrm{~s},{ }^{14}$ but it is only in the last few years that careful experiments have shown that this treatment may produce the biological effects required to prevent restenosis without unacceptable side effects. These experiments have studied the in vitro effects on cultured smooth muscle and endothelial cells and their relation to extracellular matrix, the uptake and distribution of photosensitisers in the arterial wall, the effects of PDT on normal arteries, photosensitisation of experimental atheroma, and the effects of PDT on the arterial wall after injury.

\section{In vitro observations}

In vitro experiments have shown that PDT of extracellular matrix causes a reduction in smooth muscle cell attachment, proliferation, and migration..$^{15}$ In contrast, induction of endothelial migration and proliferation has been observed following PDT. Inhibition of the effects of extracellular matrix basic fibroblastic growth factor in vitro results in a reduction in smooth muscle cell proliferation, an effect reflecting growth factor inactivation rather than denaturation of the growth factor binding sites. ${ }^{16}$ Similarly, PDT of smooth muscle cells co-cultured with platelet derived growth factor resulted in a reduction in smooth muscle cell collagen production and may be important in limiting the fibrotic healing response after balloon injury. ${ }^{17}$ In addition, PDT has been shown to increase collagen cross linkage in the extracellular matrix, creating a barrier to smooth muscle cell migration. ${ }^{18}$ It has been suggested that inactivation of transforming growth factor $\beta$ (TGF $\beta$ ) by PDT is responsible, at least in part, for the rapid endothelial cell regrowth observed in animal models within two weeks of PDT. ${ }^{19}$ These specific effects of PDT on smooth muscle and endothelial cells and associated cytoregulatory molecules provide important insights into its biological effects on the vessel wall and the mechanisms involved in the inhibition of intimal hyperplasia with this technique.

\section{Tissue uptake of photosensitiser}

The first sensitiser to be applied to atheromatous arteries was porfimer sodium (Photofrin) and this was done on necropsy tissue. ${ }^{14}$ More recent in vivo work has looked particularly at aluminium sulfonated phthalocyanine (AlSPc), 5-aminolaevulinic acid (5-ALA), and the texaphyrins. ${ }^{20-22}$ 5-ALA is not itself a photosensitiser. It is an endogenous precursor in the biosynthesis of haem, which is converted in vivo into the photoactive metabolite, protoporphyrin IX. 5-ALA production is normally limited by a feedback loop from haem, but if this is bypassed by excess exogenous 5-ALA there is a build up of protoporphyrin IX, as the final conversion of the latter to haem then becomes the rate limiting step in haem synthesis. $^{23}$

Most photosensitisers fluoresce, so their distribution in tissue can be studied by fluorescence microscopy of biopsies taken at different times after administration of the drug. Following systemic administration, both AlSPc and protoporphyrin IX show a dose and time dependent uptake into the intima, media, and adventitia of the arterial wall. ${ }^{20}{ }^{21}$ 5-ALA is attracting particular interest at present. Experiments have shown that there are high concentrations of protoporphyrin IX in the media of pig arteries 4-6 hours after intravenous administration, ${ }^{21}$ and also that PDT effects can be limited to the arterial wall, with no effect on other adjacent tissues. The drug can be given by mouth, and skin photosensitivity is limited to $24-48$ hours. ${ }^{24}$ Side effects at the clinical dose of $60 \mathrm{mg} / \mathrm{kg}$ are few, although they do include mild nausea and a transient rise in liver transaminases. Protoporphyrin IX has a convenient absorption peak at $635 \mathrm{~nm}$ in the red part of the visible spectrum.

Several investigators have explored the concept of local delivery of photosensitiser to the arterial wall, using various drug delivery systems including porous and channelled balloons and needle injection catheters. ${ }^{22} 2526$ This concept is appealing, but while local uptake may be achieved these techniques of photosensitiser delivery have little to offer over systemic administration in view of the difficulty in achieving uniform sensitisation over the area of interest.

\section{Biological effects in the normal arterial wall}

PDT of the normal rat and porcine arterial wall induces a unique biological response, the most striking features of which are endothelial denudation and a dose dependent eradication of medial smooth muscle cells ${ }^{2027}$ (fig 2). Perhaps one of the most interesting features is that these histological changes, evident within three days of treatment and independent of the sensitiser used, occur in the absence of a localised inflammatory reaction. This observation suggests that the main mechanism of cell damage in vivo may be apoptosis. Very recently, using the techniques of TUNEL (TdT mediated dUDP-biotin 3'-OH nick end labelling), transmission electron microscopy, and DNA fragmentation, LaMuraglia and colleagues 

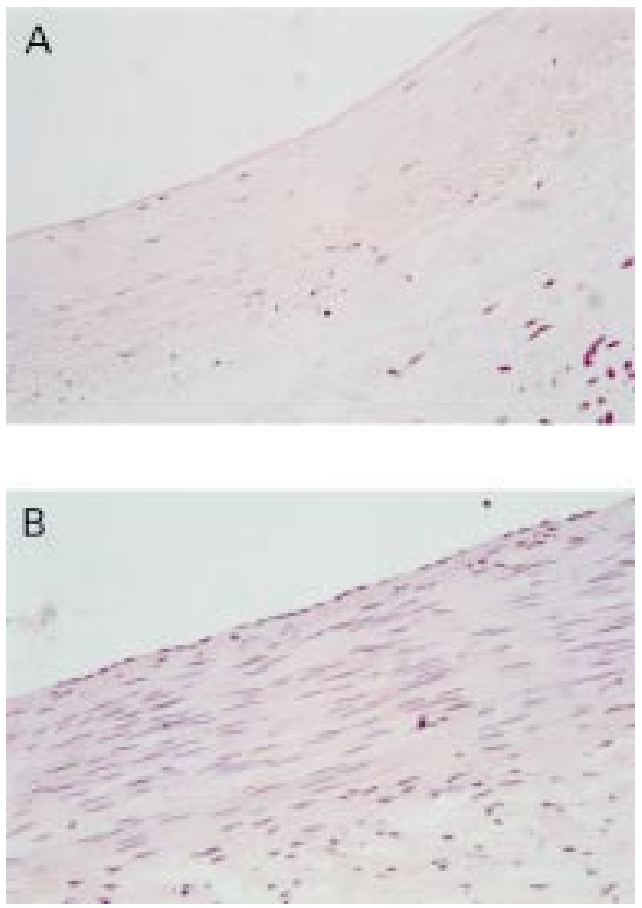

Figure 2 Photomicrograph ( $\times 400$ magnification) of haematoxylin and eosin stained sections of pig coronary artery. Histological changes observed three days after photodynamic therapy (PDT) (top) include endothelial denudation and medial smooth muscle cell eradication. The PDT regime involved local light delivery $\left(50 \mathrm{f} / \mathrm{cm}^{2}\right.$ at a wavelength of $635 \mathrm{~nm}$ from a copper vapour dye laser), using a modified standard angioplasty catheter 4-6 hours after systemic sensitisation with 5-aminolaevulinic acid $(A L A)$. A normal untreated vessel is shown for comparison (bottom).

have shown that the neointimal and medial cell depletion observed after PDT of rat carotid arteries with intimal hyperplastic is caused by apoptosis, the effect being confined to the PDT treatment field. ${ }^{28}$

These predictable and rapid histological alterations in the vessel are, however, reversible. Re-endothelialisation of the endoluminal surface has been reported in both the rat and the pig to be complete by 14 days. ${ }^{2127}$ In vitro work on bovine endothelial cells shows increased endothelial proliferation following PDT, which may be the result of inactivation of TGF $\beta .^{1529}$ The rapid regeneration of endothelium contrasts with the finding after brachytherapy, where it has been proposed that persistent endothelial loss is the cause of late thrombotic occlusion. ${ }^{8}$ In comparison with the rapid restoration of the endothelial surface, medial repopulation by smooth muscle cells is delayed after PDT. Indeed PDT of normal rat carotid arteries using 5-ALA can result in medial smooth muscle cell depletion for up to six months. ${ }^{27}$

Despite this dramatic alteration in the normal cellular architecture, these changes are not associated with thrombosis, haemorrhage, or aneurysmal dilatation of the vessel wall..$^{21}$ However, one obvious concern over the loss of medial smooth muscle cells after PDT was the effect that this would have on the structural integrity of the vessel wall. A reassuring observation is that there does not seem to be a significant alteration in the collagen and elastin components of the vessel wall after PDT. ${ }^{30}$ In addition, Grant and colleagues have shown in a rabbit carotid model that the mechanical properties of the vessel are unaffected after PDT $^{31}$; using the sensitisers 5-ALA and AlSPc, arteries treated with PDT had higher intraluminal hydrostatic burst pressures than untreated control vessels. The explanation for this may relate to the finding of increased collagen cross linkage after PDT. ${ }^{18}$

\section{Photosensitisation and PDT of experimental atheroma}

In 1983, Spears and colleagues showed selective uptake of haematoporphyrin derivative into experimental atheromatous plaques in the aortas of rabbits and Patas monkeys. ${ }^{14}$ This sensitisation of atheroma has been confirmed in other experimental models as well as in human atheroma specimens obtained at necropsy, using other porphyrin derivatives as sensitising agents. ${ }^{32} 33$ More recently, the preassociation of benzoporphyrin derivative with low density lipoprotein has been shown to enhance accumulation of this sensitiser in the plaques of a rabbit model of atherosclerosis. ${ }^{34}$ Water soluble sensitisers, such as the new agent motexafin lutitium, may bind with circulating lipoproteins to form LDL sensitiser complexes in plasma, facilitating uptake into atheroma. ${ }^{22}$

The observations of plaque photosensitisation were followed by reports of plaque regression when experimental atheromatous plaques in rabbit carotids were exposed to light. ${ }^{35}{ }^{36}$ The results in a model of experimental atheroma induced in the coronary arteries of Yucatan miniswine by balloon injury and a high cholesterol diet were less encouraging, with an improvement in angiographic stenosis in only seven of 12 arteries treated with PDT using Photofrin. ${ }^{37}$ The work of Hayashi and colleagues in 1996 provided some insight into the mechanisms involved in plaque regression by revealing alterations in lipid chemistry and a depletion of cholesterol esters following PDT of cholesterol-rich plaques in rabbits. ${ }^{38}$ Motexafin lutetium (Lu-Tex, Antrin injection) localises in macrophages within atheromatous plaque and has been shown recently to reduce both plaque mass and the number of arterial wall macrophages on exposure to light in a hypercholesterolaemic rabbit model. ${ }^{22}$ This may limit the macrophage associated inflammation that is a critical determinant of plaque stability.

\section{PDT and the vessel wall reaction to injury}

Dartsch and associates showed that cultured smooth muscle cells from both stenotic and restenotic lesions from human atherectomy specimens could be killed by incubation with porfimer sodium and exposure to ultraviolet light. ${ }^{39}$ These important observations on the cells that are in part responsible for the development of intimal hyperplasia paved the way for a series of experimental studies on the effects of PDT after balloon injury in both small and large animal models. 
SMALL ANIMAL STUDIES

In 1992 Ortu and colleagues reported a reduction in intimal hyperplasia following PDT of balloon injured rat carotid arteries. ${ }^{30}$ The sensitiser chloraluminium sulfonated phthalocyanine was used, and light was delivered to the adventitial surface of the vessel either two or seven days after injury. All the vessels were harvested 14 days after the initial injury. Other groups have similarly reported reductions in intimal hyperplasia when PDT has been applied at different time points after initial arterial balloon injury in rabbits and rats. ${ }^{40}{ }^{41}$ The decrease in intimal hyperplasia after PDT is associated with endothelial denudation, medial cell depletion, a reduction in adventitial myofibroblasts, and a striking absence of an inflammatory reaction. Healing is similar to that seen after PDT to uninjured arteries. Repopulation of medial smooth muscle cells is delayed compared with the rapid restoration of endothelial integrity. ${ }^{27} 41$

These early studies focused on the effects of PDT on developing or established intimal hyperplasia. Using 5-ALA and an extravascular light source, Nyamekye and colleagues showed that PDT given at the time of rat carotid balloon injury completely abolished the intimal hyperplastic response at 14 and 28 days. ${ }^{27}$ In the same model complete inhibition of intimal hyperplasia was seen four weeks after treatment with the sensitiser aluminium disulfonated phthalocyanine. The reduction in intimal hyperplasia in actively treated vessels compared with controls persisted for up to 26 weeks. $^{42}$

Similar effects may even be attainable in transplanted veins. Vein grafting for arterial disease is associated with intimal hyperplasia both within the conduit and at the anastomosis site. There has been limited work in this area on the effects of PDT. One study in a rat vein graft model showed that PDT with the sensitiser chloraluminium sulfonated aluminium reduced the degree of intimal hyperplasia within the venous conduit but had little effect on neointima formation at the anastomosis site. ${ }^{43}$

PDT IN THE PIG CORONARY AND PERIPHERAL CIRCULATION

The pig has become widely accepted as a suitable model for balloon angioplasty in the assessment of new interventional techniques and strategies to combat restenosis. For PDT studies it is proving particularly useful for assessing endoluminal techniques for light delivery that could be used clinically. Thin flexible cylindrical diffusers that can be attached to the end of an optical fibre can be incorporated into endovascular systems for light delivery, illuminating the arterial wall circumferentially from within the lumen. In early studies, these fibreoptic filaments were passed directly into the vessel lumen, but blood between the treatment field and the light source reduces the efficiency of light delivery, and bare fibres cannot be centred in the arterial lumen. ${ }^{44}$ An alternative is to modify a standard angioplasty catheter. A laser fibre can be placed

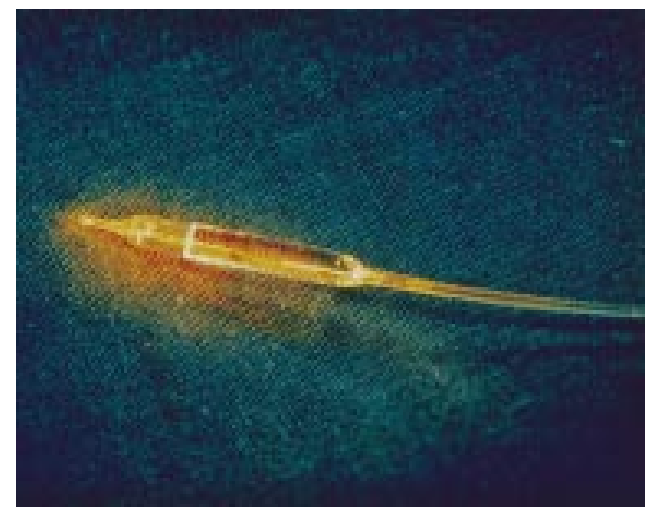

Figure 3 Modification of a standard transparent Asuka angioplasty balloon for endovascular light delivery. A 100 $\mu \mathrm{m}$ laser fibre with a distal diffuser is placed in the guide wire lumen such that the diffuser is located in the balloon segment, allowing circumferential illumination through the entire balloon surface area.

within the guide wire channel of a transparent balloon catheter and positioned so that the diffuser at the tip of the fibre is located within the balloon segment (fig 3). ${ }^{21}$ Blood is excluded from the lumen of the artery during balloon inflation, and with the balloon inflated the fibre is centred in the arterial lumen, allowing even illumination of the arterial wall. In the coronaries, there is a risk of ischaemia with prolonged balloon inflation and so repeated deflations may be necessary during illumination to minimise the risk of hypoxic injury.

Several groups have looked at the effects of PDT on injured pig arteries. In one study Gonschior and colleagues used a porous balloon catheter for local delivery of the photosensitiser Photofrin in pig femoral arteries injured with a directional atherectomy device. ${ }^{45}$ Four groups of animals were investigatedcontrol groups with injury alone, injury and sensitiser only, injury and laser light only, and one actively treated group receiving both injury and PDT (sensitiser and light). Light was delivered by a fibreoptic filament placed directly into the artery. Arteries treated with PDT showed a significant reduction in medial:intimal hyperplasia ratio at 21 days compared with control injured vessels (mean (SD): 0.3 $(0.2) v 1.0(0.5), \mathrm{p}<0.001)$, with a reduction in restenosis from $30(10) \%$ to $3(2) \%$ $(\mathrm{p}<0.01)$. There were no differences in the areas subtended by either the internal or the external elastic lamina, suggesting that local PDT had no effect on arterial remodelling. No significant effects were seen in the control groups of sensitiser or light alone.

We have used a modified standard balloon angioplasty catheter for light delivery (fig 4) in a pig model of coronary and iliac balloon injury. Using 5-ALA we found a significantly larger lumen area 28 days after PDT than in balloon injured control vessels not receiving PDT $\left(1.4 v 0.8 \mathrm{~mm}^{2}, \mathrm{p}=0.002\right) .{ }^{46}$ This was partly because of a reduction in neointima formation $\left(0.4 v 0.7 \mathrm{~mm}^{2}, \mathrm{p}=0.06\right)$, but the main reason was an increase in total vessel area, represented by the area subtended by the external elastic lamina $\left(2.8 v 2.2 \mathrm{~mm}^{2}, \mathrm{p}=0.006\right)$, which was unchanged from the reference 


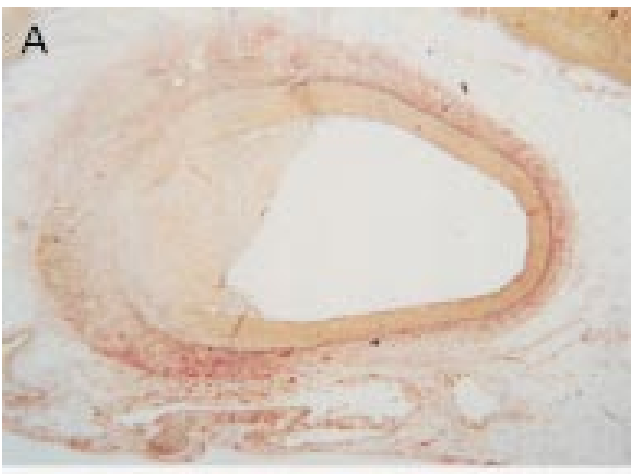

B

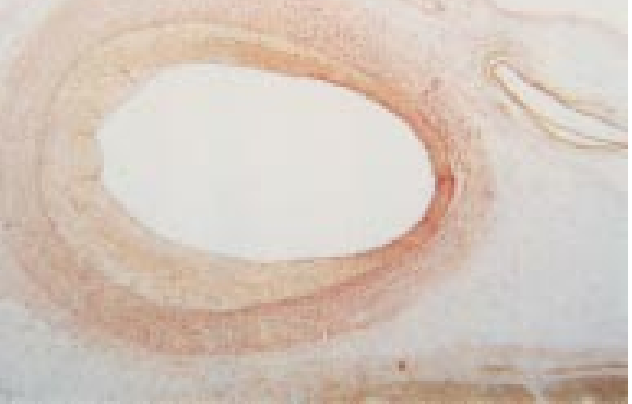

Figure 4 Photomicrograph ( $\times 40$ magnification) of elastin van Giessen stained sections of pig circumflex artery 28 days after oversized balloon injury. The balloon injured days after oversized balloon injury. The balloon injured
control artery (top) shows a greater neointimal area and reduced lumen size than the balloon injured artery that received photodynamic therapy (PDT) (bottom). The PDT regimen involved local light delivery $\left(50 \mathrm{~F} / \mathrm{cm}^{2}\right.$ at a wavelength of $635 \mathrm{~nm}$ from a copper vapour dye laser) using a modified standard angioplasty catheter 4-6 hours after systemic sensitisation with 5-aminolaevulinic acid $(A L A)$.

section of the same vessel $\left(1.5 v 1.6 \mathrm{~mm}^{2}\right)$. The conclusion from this was that improved lumen size after PDT to balloon injured arteries resulted from an absence of the negative remodelling observed after balloon injury alone, as well as from a reduction in neointima formation. This was the first time that PDT had been shown to influence the remodelling process, which we now know to be an important component of the vessel wall response to injury. Similar trends, although less striking, were seen in balloon injured iliac vessels treated with PDT. Interestingly, and perhaps reassuringly, medial smooth muscle cell numbers 28 days after treatment were not significantly different in PDT treated vessels and in controls, suggesting that repopulation of the arterial media had occurred in this time period.

\section{PDT and intracoronary stenting}

There are currently no data relating to the effects of PDT after stenting in peripheral or coronary vessels, although the application of low power red light alone has been shown to reduce intimal hyperplasia in a porcine model of intracoronary stenting, perhaps by activating endogenous porphyrins. ${ }^{47}$ Clinically important restenosis is seen less often after stenting than after standard angioplasty because of the beneficial effects on vessel recoil and remodelling. However, neointima formation associated with stenting is often more pronounced than after standard angioplasty and is particularly concentrated around the stent struts. The favourable effects of PDT on intimal hyperplasia after angioplasty suggest that the technique might be of value in the prevention, and perhaps even the treatment, of in-stent restenosis. This is an area currently under investigation.

\section{Clinical applications of endovascular PDT}

Clinical experience with vascular PDT is limited. A pilot clinical study of adjuvant PDT in patients undergoing repeat femoral angioplasty for restenosis showed the technique to be safe and effective. ${ }^{48}$ Seven patients (with eight lesions, of which three were vessel occlusions) sensitised with oral 5-ALA $(60 \mathrm{mg} / \mathrm{kg})$ received laser light through a standard transparent angioplasty balloon. Light was delivered to the sensitised arteries by replacing the angioplasty balloon guide wire with a $0.2 \mathrm{~mm}$ optical fibre. Follow up was with duplex scanning and intravenous digital subtraction angiography at six months. At that time all patients were asymptomatic. Peak systolic velocity ratios were less than 2.0 (the criterion for restenosis), with no evidence of restenosis on digital subtraction angiography. No arterial complications were noted. Long term results for these patients have remained excellent (Mansfield RJR and colleagues, unpublished observations). The mean (SD) follow up period in the seven patients has been 26 (3) months. Six have remained asymptomatic, although one required repeat angioplasty to two of the original treatment sites at one year. Four patients consented to repeat duplex scanning, and only one of these was found to have Doppler evidence of restenosis. That patient was the only one originally recruited with an arterial occlusion who was symptomatic, with mild unlimiting claudication recurring at 18 months. No arterial complications have occurred in these patients.

A phase 1 clinical study of PDT in 47 patients using motexafin lutetium in the treatment of de novo iliofemoral atheromatous plaque, without previous percutaneous angioplasty, has recently been reported. ${ }^{49}$ Side effects were mild (paraesthesiae and rash), and arterial complications of the treatment were not encountered. Objective efficacy data for this agent in the treatment of peripheral vascular disease are awaited.

\section{Limitations of PDT}

With all new technologies there are inherent limitations. On the face of it PDT has considerable potential as a safe and effective way of preventing restenosis after percutaneous coronary intervention, although no data are yet available on how stented arteries will respond. The application of non-thermal laser light does not appear to have any deleterious effects on the vessel wall in the long term. The early regeneration of endothelium after the initial treatment may provide an advantage over 
treatments such as brachytherapy, where persistent endothelial loss has been suggested as the cause of late thrombotic occlusion of the vessel. DNA damage is not a feature of PDT, and the risk of mutagenicity following treatment is low. Results from cancer patients confirm that the technique is readily repeatable without any long term consequences, and risks to staff are negligible.

One of the most important safety aspects, if this is to be a viable interventional technique, will be to guarantee the integrity of the laser fibres. Technological advances will be needed, to develop appropriately modified angioplasty balloons. The current development of small portable lasers that can be easily transported and operated routinely by catheter laboratory staff will make the technique easy to apply and relatively inexpensive. Another important consideration is tolerance to the photosensitising agents and their safety profile. Many of the early drugs used in oncology were limited by prolonged cutaneous photosensitivity. The new generation of drugs such as 5-ALA, which can be given orally and which clears from the body within a couple of days, are much more attractive for clinical practice in this regard.

\section{Summary}

PDT uses non-thermal laser light targeted at the arterial wall to activate previously injected photosensitising agents. The resulting histological changes are associated with a reduction in neointima formation and the absence of negative vessel wall remodelling. It has been used successfully in a pilot clinical trial of peripheral vascular disease and, while further research still needs to be carried out, PDT has promise as a new strategy for the prevention and treatment of restenosis after percutaneous coronary intervention.

RM is supported by a British Heart Foundation training fellowship.

1 Holmes DR, Vlietstra RE, Smith HC, et al. Restenosis after percutaneous transluminal coronary angioplasty (PTCA): a report from the PTCA Registry of the National Heart, Lung, and Blood Institute. $\mathrm{Am} \mathcal{F}$ Cardiol 1984;53:77-81C

2 Nobuyoshi M, Kimura T, Nosaka H, et al. Restenosis after successful percutaneous transluminal coronary angioplasty: serial angiographic follow-up of 229 patients. $\mathcal{F}$ Am Coll Cardiol 1988;12:616-23.

3 Davies MG, Hagen PO. Pathobiology of intimal hyperplasia. Br F Surg 1994;81:1254-69.

4 Bauters C, Isner JM. The biology of restenosis. Prog Cardiovasc Dis 1997;40:107-16.

5 Landzberg BR, Frishman WH, Lerrick K. Pathophysiology and pharmacological approaches for prevention of coronary artery restenosis following coronary artery balloon ary artery restenosis following coronary artery balloon
angioplasty and related procedures. Prog Cardiovasc Dis angioplasty and

6 Serruys PW, de Jaegere P, Kiemeneij F, et al. A comparison of balloon-expandable-stent implantation with balloon angioplasty in patients with coronary artery disease. Benestent Study Group. N Engl f Med 1994;331:489-95.

7 Kuntz RE, Baim DS. Prevention of coronary restenosis: the evolving evidence base for radiation therapy. Circulation 2000;101:2130-3.

8 Costa MA, Sabat M, van der Giessen WJ, et al. Late coronary occlusion after intracoronary brachytherapy. Circulation 1999;100:789-92.

9 Dougherty TJ, Gomer CJ, Henderson BW, et al. Photodynamic therapy. F Natl Cancer Inst 1998;90:889-905.

10 Henderson BW, Dougherty TJ. How does photodynamic therapy work? Photochem Photobiol 1992;55:145-57.

11 Granville DJ, Shaw JR, Leong S, et al. Release of cytochrome C, Bax migration, Bid cleavage, and activation of caspases $2,3,6,7,8$, and 9 during endothelial cell apoptosis. Am f Pathol 1999;155:1021-5.
12 Heckenkamp J, Leszczynski D, Schiereck J, et al. Different effects of photodynamic therapy and gamma-irradiation on vascular smooth muscle cells and matrix: implications for inhibiting restenosis. Arterioscler Thromb Vasc Biol 1999;19: 2154-61

13 Hsi RA, Rosenthal DI, Glatstein E. Photodynamic therapy in the treatment of cancer: current state of the art. Drugs 1999;57:725-34

14 Spears JR, Serur J, Shropshire D, et al. Fluorescence of experimental atheromatous plaques with hematoporphyrin derivative. $\mathcal{F}$ Clin Invest 1983;71:395-9.

15 Adili F, Statius van Eps RG, Karp SJ, et al. Differential modulation of vascular endothelial and smooth muscle cell function by photodynamic therapy of extracellular matrix: novel insights into radical-mediated prevention of intimal hyperplasia. I Vasc Surg 1996;23:698-705.

16 LaMuraglia GM, Adili F, Karp SJ, et al. Photodynamic therapy inactivates extracellular matrix-basic fibroblast growth factor: insights to its effect on the vascular wall. $f$ growth factor: insights to its
Vasc Surg 1997;26:294-301.

17 Statius van Eps RG, Mark LL, Schiereck J, et al. Photodynamic therapy inhibits the injury-induced fibrotic response of vascular smooth muscle cells. Eur 7 Vasc Endovasc Surg 1999;18:417-23

18 Overhaus M, Heckenkamp J, Kossodo S, et al. Photodynamic therapy generates a matrix barrier to invasive vascular cell migration. Circ Res 2000;86:334-40.

19 Statius van Eps RG, Adili F, Watkins MT, et al. Photodynamic therapy of extracellular matrix stimulates endothelial cell growth by inactivation of matrix-associated transforming growth factor-beta. Lab Invest 1997;76:25766.

20 Grant WE, Speight PM, MacRobert AJ, et al. Photodynamic therapy of normal rat arteries after photosensitisation using disulphonated aluminium phthalocyanine and 5-aminolaevulinic acid. Br f Cancer 1994;70:72-8.

21 Jenkins MP, Buonaccorsi G, MacRobert A, et al. Intraarterial photodynamic therapy using 5-ALA in a swine model. Eur 7 Vasc Endovasc Surg. 1998;16:284-91.

22 Hayase M, Woodbum KW, Perlroth J, et al. Photoangioplasty with local motexafin lutetium delivery reduces macrophages in a rabbit post-balloon injury model. Cardiovasc Res 2001;49:449-55.

23 Rimington C. Porphyrin and haem biosynthesis and its control. Acta Med Scand 1966;179(suppl 445):11-45.

24 Webber J, Kessel D, Fromm D. Side effects and photosensitization of human tissues after aminolevulinic acid. F Surg Res 1997;68:31-7.

25 Gonschior P, Pahl C, Huehns TY, et al. Comparison of local intravascular drug-delivery catheter systems. Am Heart $\mathcal{f}$ 1995;130:1174-81.

26 Visona A, Angelini A, Gobbo S, et al. Local photodynamic therapy with $\mathrm{Zn}$ (II)-phthalocyanine in an experimental model of intimal hyperplasia. 7 Photochem Photobiol B $2000 ; 57: 94-101$.

27 Nyamekye I, Anglin S, McEwan J, et al. Photodynamic therapy of normal and balloon-injured rat carotid arteries using 5-amino-levulinic acid. Circulation 1995;91: 417-25.

28 LaMuraglia GM, Schiereck J, Heckenkamp J, et al. Photodynamic therapy induces apoptosis in intimal hyperplastic arteries. Am f Pathol 2000;157:867-75.

29 Statius van Eps RG, LaMuraglia GM. Photodynamic therapy inhibits transforming growth factor beta activity associated with vascular smooth muscle cell injury. $f$ Vasc Surg 1997;25:1044-52.

30 Ortu P, LaMuraglia GM, Roberts WG, et al. Photodynamic therapy of arteries. A novel approach for treatment of experimental intimal hyperplasia. Circulation 1992;85: $1189-96$.

31 Grant WE, Buonaccorsi G, Speight PM, et al. The effect of photodynamic therapy on the mechanical integrity of normal rabbit carotid arteries. Laryngoscope 1995;105: $867-71$

32 Kessel D, Sykes E. Porphyrin accumulation by atheromatous plaques of the aorta. Photochem Photobiol 1984;40:5961.

33 Hsiang YN, Crespo MT, Richter AM, et al. In vitro and in vivo uptake of benzoporphyrin derivative into human and miniswine atherosclerotic plaque. Photochem Photobiol 1993;57:670-4.

34 Allison BA, Crespo MT, Jain AK, et al. Delivery of benzoporphyrin derivative, a photosensitizer, into atherosclerotic plaque of Watanabe heritable hyperlipidemic rabbits and balloon-injured New Zealand rabbits. Photochem Photobiol 1997;65:877-83.

35 Litvack F, Grundfest WS, Forrester JS, et al. Effects of hematoporphyrin derivative and photodynamic therapy on atherosclerotic rabbits. Am f Cardiol 1985;56:667-71.

36 Neave V, Giannotta S, Hyman S, et al. Hematoporphyrin uptake in atherosclerotic plaques: therapeutic potentials. Neurosurgery 1988;23:307-12.

37 Hsiang YN, Crespo MT, Machan LS, et al. Photodynamic therapy for atherosclerotic stenoses in Yucatan miniswine. Can $\mathcal{F}$ Surg 1994;37:148-52.

38 Hayashi J, Saito T, Aizawa K. Change in chemical composition of lipids accumulated in atheromas of rabbits following photodynamic therapy. Lasers Surg Med 1997; 21:287-93.

39 Dartsch PC, Ischinger T, Betz E. Responses of cultured smooth muscle cells from human non-atherosclerotic arteries and primary stenosing lesions after photoradiation: implications for photodynamic therapy of vascular stenoses. $\mathcal{F}$ Am Coll Cardiol 1990;15:1545-50. 
40 Eton D, Colburn MD, Shim V, et al. Inhibition of intimal hyperplasia by photodynamic therapy using photofrin. $\mathcal{F}$

41 LaMuraglia GM, ChandraSekar NR, Flotte TJ, et al. Photodynamic therapy inhibition of experimental intimal hyperplasia: acute and chronic effects. F Vasc Surg 1994;19: $321-9$

42 Nyamekye I, Buonaccorsi G, McEwan J, et al. Inhibition of intimal hyperplasia in balloon-injured arteries with adjunctive phthalocyanine sensitised photodynamic therapy. Eur $f$ Vasc Endovasc Surg 1996;11:19-28.

43 Lamuraglia GM, Klyachkin ML, Adili F, et al. Photodynamic therapy of vein grafts: suppression of intimal hyperplasia of the vein graft but not the anastomosis. 7 Vasc Surg 1995;21:882-90.

44 Vincent GM, Fox J, Charlton G, et al. Presence of blood significantly decreases transmission of $630 \mathrm{~nm}$ laser light. Lasers Surg Med 1991;11:399-403.
45 Gonschior P, Gerheuser F, Fleuchaus M, et al. Local photodynamic therapy reduces tissue hyperplasia in an experi-

46 Jenkins MP, Buonaccorsi GA, Mansfield R, et al. Reduction in the response to coronary and iliac artery injury with photodynamic therapy using 5-aminolaevulinic acid. Cardiovasc Res 2000;45:478-85.

47 De Scheerder IK, Wang K, Zhou XR, et al. Intravascular low power red laser light as an adjunct to coronary stent implantation evaluated in a porcine coronary model. $\mathcal{f}$ Invasive Cardiol 1998;10:263-8.

48 Jenkins MP, Buonaccorsi GA, Raphael M, et al. Clinical study of adjuvant photodynamic therapy to reduce restenosis following femoral angioplasty. Br f Surg 1999;86:1258-63.

49 Rockson SG, Kramer P, Razavi M, et al. Photoangioplasty for human peripheral atherosclerosis: results of a phase I trial of photodynamic therapy with motexafin lutetium (Antrin). Circulation 2000;102:2322-4.

\section{IMAGES IN CARDIOLOGY}

\section{Primary cardiac lymphoblastic $\mathrm{T}$ cell lymphoma}

A 52 year old man was admitted to our hospital because of ventricular tachycardias. After electrical cardioversion, the patient reported a weight loss of $7 \mathrm{~kg}$ and nocturnal sweating during the previous weeks. Laboratory investigations showed moderate anaemia and a slightly raised white blood count with normal differential count. Echocardiography revealed thickened and hypokinetic posterior and lateral walls of the left ventricle. Ultrafast computed tomography (CT) confirmed the thickened walls (top right), which rapidly increased from $16 \mathrm{~mm}$ to $30 \mathrm{~mm}$ end diastolic diameter over the next two weeks. Coronary angiography detected de novo formation of tumour vessels in the apical wall of the left ventricle. Endomyocardial biopsy from the thickened left ventricular wall was performed and revealed lymphoma. Immunophenotyping demonstrated $\mathrm{T}$ cell lymphoblastic lymphoma. Cranial and abdominal CT, thoracic nuclear magnetic resonance tomography, bronchoscopy, as well as bone marrow and spinal fluid specimens revealed no other manifestation of the lymphoma. Polychemotherapy was started with cyclophosphamide, vincristine, daunorubicine, prednisone and, later, L-asparaginase, and was well tolerated. After six days, thickness of the infiltrated wall had decreased to $15 \mathrm{~mm}$ and left ventricular function had improved.

Nineteen days later the patient died suddenly because of interminable ventricular fibrillation. Necropsy findings showed extensive lymphomatous infiltration and necrosis of the posterior and lateral wall of the left ventricle (bottom right) which may have been the focus for the renewed ventricular fibrillation.
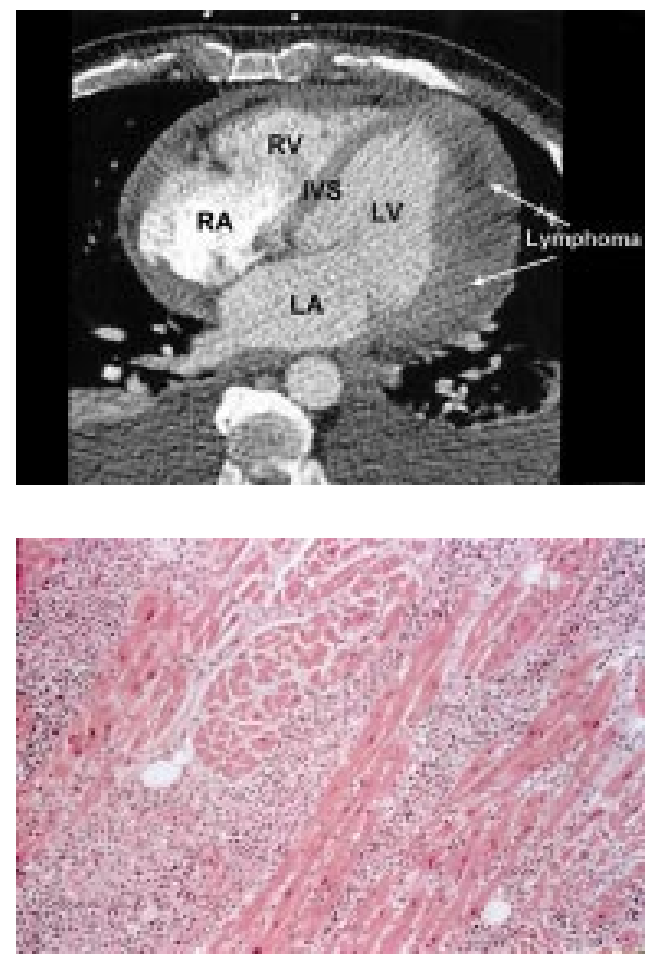

Hence, in this case ventricular arrhythmias caused by extensive necrosis limited survival in spite of the therapeutic effect of polychemotherapy.

DIERK WERNER

ALEXANDER SCHMEISSER WERNER G DANIEL dierk.werner@nexgo.de 